\title{
Effect of Thermoplastic as Fine Aggregate to Concrete Mixture
}

\author{
Tomas U. Ganiron Jr \\ Graduate School, Adamson University, Manila \\ College of Architecture, Qassim University, Buraidah City \\ tomasuganironjr@gmail.com
}

\begin{abstract}
This paper outlines an experimental study that measures the effects of thermoplastic when added to concrete cement and needs of the ecological sector in terms of recycling the waste plastic that harms not only the soil structure and the environment as per say but as well as the human who without their knowledge damage their health because of the degradation of this product.

The plastic was grounded into pieces for concrete mixture, where it substitutes the 5\% of the fine aggregate, which is the sand. It then undergoes to strength test that investigate whether it can pass or at least equal the standard specification of concrete mix for wall panel. The experimentation went through moisture content test, specific gravity. test, slump test, sieve analysis, compressive test and flexural test.
\end{abstract}

Keywords: Concrete mixture, fine aggregate, recycled material, thermoplastic material, waste material

\section{Introduction}

With an increased in environmental problems, especially those materials that are non biodegradable caused too much predicament on the ecological sector. The primary material among this waste product is the plastic substance. Plastic with its exclusive qualities of being light yet storing and economical, had invaded every aspect of our day to- day life. It has many advantages; it is durable, light, easy to mold and can be adapted to different user requirements $[1,3]$. Once hailed as a "wonder material", plastic is now a serious environmental and health concern, here in our country and around the world, essentially due to its non-biodegradable nature [2].

Although people know that plastics have a remarkable impact, it has become increasingly obvious that there is a price to be paid for their use. Plastics are durable and can degrade slowly. In some instance, burning it can cause toxic fumes on our air $[4,5]$.

Plastics are used in a wide range of applications and some plastics items, such as food packaging, become waste only a short time after purchase. Other plastic items lend themselves to be reused many times over.

Reusing plastic is preferable to recycling as it uses less energy and fewer resources. Long life, multi-trip plastics packaging has become more widespread in recent years, replacing less durable and single-trip alternatives, so reducing waste [6]. For example, the major supermarkets have increased their use of returnable plastic crates for transport and display purposes four-fold from 8.5 million in 1992 to an estimated 55.8 million in 2012. They usually last up to 30 years and can be recycled at the end of their useful life. . 
According to a 2012 Environment Agency report, 80\% of post-consumer plastic waste is sent to landfill, $8 \%$ is incinerated and only $7 \%$ is recycled [7,9]. In addition to reducing the amount of plastics waste requiring disposal, recycling plastic can have several other advantages: A.) Conservation of non-renewable fossil fuels - Plastic production uses $8 \%$ of the world's oil production, $4 \%$ as feedstock and $4 \%$ during manufacture. B.) Reduced consumption of energy. C.) Reduced amounts of solid waste going to landfill. D.) Reduced emissions of carbon dioxide (CO2), nitrogen-oxide (NO) and sulfur-dioxide (SO2).

Currently most plastic recycling is of 'process scrap' from industry, i.e. polymers left over from the production of plastics. This is relatively simple and economical to recycle, as there is a regular and reliable source and the material described as reprocessing rather than recycling.

The creation of non-decaying materials, combined with a growing consumer population, has resulted in a waste disposal crisis. One solution to this crisis lies in recycling waste plastic into useful products $[10,11,12]$.

Research into new and innovative uses of waste thermoplastic materials is continually advancing. Many agencies, private organizations, and individuals have completed or are in the process of completing a wide variety of studies and research projects concerning the feasibility, environmental suitability, and performance of using recycled products in highway construction. These studies try to match society's need for safe and economic disposal of waste thermoplastic materials with the construction industry's need for better and more cost effective construction materials.

From this fact, everyone knows that plastic harms the environment. And that it takes hundreds of years to break it down. But as they break down, they release poisonous materials into the water and soil. It strangles our wildlife, and even endangered species die because they eat them.

Therefore, re-using this not only in a sense of recycling but also in application to other industries had leaded us to inference that it can be used to construction material. Building industry can explore on this to develop it in its full potential in building and construction manufacturing.

Due to the un-ending use of waste plastic, or more considerably thermoplastic that continuously becomes one of environmental problem because of its non-biodegradable nature, the study paves the way for the recognition of using the waste thermal plastic as an admixture to the concrete cement for construction industry [13].

This study alleviates the crisis in decomposition of non-biodegradable thermoplastic as well as the improvement of construction material to solve the incessant pile up of garbage. In its whole, the research study addresses the interest of the ecosystem and the construction and building technology to enhance the natural world as well as that of the builders' material.

\section{Methodology}

In the design of an effective fine aggregate, it must primarily conform to the specified standards of insulating materials that are stated by the American Society for Testing and Materials (ASTM).

The researcher observed through experimentation the physical property which is needed for concrete mixture. Physical properties like compressive strength, tensile strength and flexural strength of concrete were tested through UTM (Universal Testing Machine). 
Conforming to the specification of ASTM C62-97 has an average compressive strength of $2500 \mathrm{psi}$ or $17.24 \mathrm{MPa}$ [14].

The cylinder test according to ASTM C39 standard (CSA A23.2-9C test method) is the test used for determining concrete compressive strength [15]. A 12 inch (305mm) high by 6 inch $(150 \mathrm{~mm})$ wide cylinder of concrete is cast and cured for the appropriate time (usually 28 days). It is then compressed between the two parallel faces. The stress at failure is taken to be the compressive strength of the concrete. It is generally expressed in pounds per square inch (psi) or Mega-Pascals (MPa) at an age of 28 days. Concrete mix strengths used in ICF (Integrated Concrete Forms) will most likely range between 2500 psi - 4000psi (17 MPa - $30 \mathrm{MPa}$ ).

Flexural Strength is the strength of concrete to bending and was measured using ASTM C78 standard (CSA A23.2-8C test method) with a simple beam and third point loading. Most general-use concrete has a flexural strength between 500 psi -700 psi (3.4 $\mathrm{MPa}-4.8 \mathrm{MPa})[16]$.

\subsection{Moisture content of the aggregate}

The moisture content of the aggregate is used to utilize the process of drying, to determine the percentage of evaporable moisture in the sample aggregate. This is use to dry the aggregate to determine its evaporated moisture whose results are sufficiently accurate for the adjustment of batch weights of concrete. The moisture in the test sample (thermal plastic) may be measures more reliably through this method.

\subsection{Specific gravity and water absorption of fine aggregate}

The specific gravity and water absorption of fine aggregate experiment is use to determine the bulk and apparent specific gravity and water absorption of fine aggregate. The bulk specific gravity is a characteristic whose major application is in the calculation of the volume occupied by the aggregate in various mixtures [17]. Such mixtures include Portland cement concrete and bituminous concrete. This is also used in the computation of voids in aggregate. In cases involving wet aggregate, the bulk specific gravity which is determined on the saturated surface - dry specimen is used.

Specific gravity is the ratio of the ass or weight in air of a unit volume of a material to the mass of the same volume of water at a given temperature. It is a dimensionless value and, as such, can be expressed as bulk specific gravity (SSD) or apparent specific gravity (ASD) and water absorption. These are all based on aggregate that has been soaked in water for 15 hours.

\subsection{Sieve Analysis}

The first thing to do is doing the sieve analysis to determine the particle size distribution of fine and coarse aggregate. The researcher crushes the thermal plastic pieces in order to segregate it using the sieve analysis. The particle size and shape and maximum size of aggregates are important in the research because of their effect on relative proportions, workability, economy, and porosity and shrinkage of the aggregates.

Sieve analysis of concrete aggregates, which is primarily used to determine the grading of aggregates materials, is a discipline that the frequently required in the field $[16,17]$. Results of this test are used as a critical basis in determining the compliance of the particle size distribution with applicable specification requirements, as in developing relationships between porosity and packing. The necessary data to control 
the production of various aggregate product and mixtures containing aggregates are also generated through this test.

Thoroughly mix and reduce to an amount suitable for testing the sample aggregate. The reduction should result in a weight of the sample that approximate the weigh desired when dry. An exact predetermined weight is not permissible.

\subsection{Slump test}

The slump test method is used to determine the slump plastic concrete, both in the laboratory and in the field, having coarse aggregate up to $1-1 / 2$ inch $(38 \mathrm{~mm})$ in size $[15,17]$. The coarse aggregate larger than 1-1/2 inch in size may undergo such test if it is made on the fraction of concrete passing a 1-1/2 inch sieve with the larger aggregate being removed. Slump test is not considered applicable to non-plastic and non-cohesive concrete.

The test specimen should be formed in a mold made of metal not thinner than number 16 gauge and impervious to cement paste. The mold should be in the form of a lateral surface of the frustum of a cone with a base diameter of 8 inch $(203 \mathrm{~mm})$, a top diameter of 4 inch $(102 \mathrm{~mm})$ and a height of 12 inch $(305 \mathrm{~mm})$. The base and the top should be left open, oriented parallel to each other and at right angles to the axis of the cone. The mold should be provided with foot pieces and handles.

The tamping rod should be a round, straight steel rod with a diameter of $5 / 8$ inch $(16 \mathrm{~mm})$ and a length of approximately 24 inch $(600 \mathrm{~mm})$, with the tamping end rounded to a hemispherical tip diameter of $5 / 8$ inch.

The research specimen is formed in a mold made of metal not thinner than number 16 gauge and impervious to cement paste and the test specimen is obtained from the concrete, representing the sample of the entire batch.

\subsection{Making and curing concrete test specimen in the laboratory}

Curing and making of concrete test specimen is done in the laboratory under accurate control of materials and test condition using concrete that can be consolidates rodding or vibration.

Cylindrical specimens for comprehensive strength, Young's Modulus of Elasticity, creep and tensile splitting may be various sizes with a minimum of 2 inch diameter by 4 inch length. For test than creep, cylindrical specimens are molded and allowed to harden with the axis of cylinder vertical; creep specimens are cast with the cylindrical axis either vertical or horizontal and allowed to harden in the position in which they are cast [17].

Unless otherwise specified by the test method of choice, prismatic specimens, including beams for flexural strength, cubes for compressive, prisms for freezing and thawing bond, length change are formed with their long axes horizontal and conform in dimensions to the requirements of the specific method.

The number of specimens and the number of test batches are dependent on the established practice and the nature of the test program. Usually three of more specimens should be prepared for such test age and test conditions unless otherwise specified.

\subsection{Compressive strength of cylindrical specimen}

The researcher use the compressive strength test to determine the compressive strength of the concrete specimens as molded in concrete cylinders with a dimension of 6 by 12 inch. 


\subsection{Flexural strength of concrete}

The researcher uses a flexural strength test to conform to the ASTM standards, its method of making and curing.

\section{Results and Discussion}

\subsection{Moisture content of the aggregate}

Table 1 shows the comparison between the plastic aggregate and the sand. It shows that the weight of moisture of the plastic is zero implying that there is no moisture even after the original sample had been dried in the oven. While the fine aggregate or sand had a $2 \mathrm{~g}, 1.5 \mathrm{~g}$ and $2 \mathrm{~g}$ in their weight of moisture. There was no difference after the original sample was oven dry in the plastic sample, as shown with $70 \mathrm{~g}$ to $70 \mathrm{~g}, 59 \mathrm{~g}$ to $59 \mathrm{~g}$, and $63 \mathrm{~g}$ to $63 \mathrm{~g}$. The moisture content is $0 \%$ for plastic while the average moisture content for the sand is $4.59 \%$.

Table 1. Moisture content of the aggregate (Plastic vs. Sand)

\begin{tabular}{|l|l|l|l|l|l|l|}
\hline Test No. & $\begin{array}{c}1 \\
\text { Plastic }\end{array}$ & $\begin{array}{c}1 \\
\text { Sand }\end{array}$ & $\begin{array}{c}2 \\
\text { Plastic }\end{array}$ & $\begin{array}{c}2 \\
\text { Sand }\end{array}$ & $\begin{array}{c}3 \\
\text { Plastic }\end{array}$ & $\begin{array}{c}3 \\
\text { Sand }\end{array}$ \\
\hline Identification of moisture container & W1 & W1 & W2 & W2 & W3 & W3 \\
\hline $\begin{array}{l}\text { Weight of the original sample aggregate + } \\
\text { container (g) }\end{array}$ & 70 & 61.5 & 59 & 55.5 & 63 & 64 \\
\hline Weight of dry aggregate + container (g) & 70 & 59.5 & 59 & 54 & 63 & 62 \\
\hline Weight of moisture (g) & 0 & 2 & 0 & 1.5 & 0 & 2 \\
\hline Weight of moisture container (g) & 21 & 21 & 16.5 & 21 & 17 & 21.5 \\
\hline Weight of dry aggregate (g) & 49 & 38.5 & 33 & 33 & 46 & 40.5 \\
\hline Moisture Content (\%) & 0 & 5.19 & 0 & 4.55 & 0 & 4.94 \\
\hline
\end{tabular}

Average moisture content: Plastic $=0 \%$, Sand $=4.89 \%$

\subsection{Specific gravity and water absorption of fine aggregate}

As shown in Table 2, the weight of flask with water for plastic is $256.3 \mathrm{~g}$, the same with sand, the temperature during test are the same as well as that of weight of flask, water and aggregate with $335.2 \mathrm{~g}$. The weight of dry aggregate both plastic and sand is 78.9 but its bulk sp/ Gr. (SSD) A / B $+\mathrm{S}-\mathrm{C}$, there's a 0.01 difference. The plastic has 1.38 while sand has 1.37 . The same with the bulk sp/ Gr. (SSD) A/ B + $500-\mathrm{C}$, there's a 0.01 difference as well, with 0.19 and 0.18 result.

Table 2. Specific gravity and water absorption of fine aggregate (Plastic vs. Sand)

\begin{tabular}{|l|l|l|}
\hline No. of trials & Plastic & Sand \\
\hline Weight of flask + water & $256.3 \mathrm{~g}$ & $256.3 \mathrm{~g}$ \\
\hline Temperature during test & $28^{\circ} \mathrm{C}$ & $28{ }^{\circ} \mathrm{C}$ \\
\hline Weight of flask + water + aggregate & $335.2 \mathrm{~g}$ & $335.2 \mathrm{~g}$ \\
\hline Weight of dry aggregate & $78.9 \mathrm{~g}$ & $78.9 \mathrm{~g}$ \\
\hline Bulk sp/ Gr. (SSD) = A/ B+S-C & 1.38 & 1.37 \\
\hline Bulk sp/ Gr. (SSD) = A/ B + 500 - C & 0.19 & 0.18 \\
\hline Apparent Sp. Gr. = A/ B+ A - C & -156.8 & -86.66 \\
\hline Absorption = S - A / A x 100 & 73.21 & 74.1 \\
\hline
\end{tabular}




\subsection{Sieve analysis}

Table 3 shows that more particles are retained on no. 40, which is $190 \mathrm{~g}$ out of 400 grams used in the test. The next sieve number that also contains a big accumulation is the number 16 sieve with $130 \mathrm{~g}$ out of 400 grams used in the test.

The percent retained on number 8 is $0 \%, 1 \%$ on $10,32.5 \%$ on $16,47.5 \%$ on 40 , $8.75 \%$ on $50,8 \%$ on 100 and $2.25 \%$ on pan. For the cumulative weight passing, the number 8 is 0 , for 10 is 396,16 is 270,40 is 210,50 is 365,100 is 368 and the pan had 391. The cumulative percent passing for 8 is $0 \%, 10$ is $99 \%, 16$ is $67.5 \%, 40$ is $52.5 \%$, 50 is $91.25 \%, 100$ is $92 \%$ and the pan has $97.75 \%$.

Although the number 40 sieve collect more particles compared to the rest, the experiment used all the grains amass passing the number 10 sieve for mixing.

Table 3. Sieve analysis

\begin{tabular}{|c|c|c|c|c|c|}
\hline $\begin{array}{c}\text { Sieve } \\
\text { no. }\end{array}$ & $\begin{array}{c}\text { Weight } \\
\text { retained }(\mathrm{g})\end{array}$ & $\begin{array}{c}\text { Retained } \\
(\%)\end{array}$ & $\begin{array}{c}\text { Cumulative } \\
\text { weight passing } \\
(\mathrm{g})\end{array}$ & $\begin{array}{c}\text { Cumulative } \\
\text { passing }(\%)\end{array}$ & $\begin{array}{c}\text { Retained } \\
(\%)\end{array}$ \\
\hline 8 & 0 & 0 & 0 & 0 & 0 \\
\hline 10 & 4 & 1 & 396 & 99 & 1 \\
\hline 16 & 130 & 32.5 & 270 & 67.5 & 32.5 \\
\hline 40 & 190 & 47.5 & 210 & 52.5 & 47.5 \\
\hline 50 & 35 & 8.75 & 365 & 91.25 & 8.75 \\
\hline 100 & 32 & 8 & 368 & 92 & 8 \\
\hline Pan & 9 & 2.25 & 391 & 97.75 & 2.25 \\
\hline Total & 400 & 100 & 0 & 0 & 100 \\
\hline
\end{tabular}

\subsection{Flexural strength}

Figure 1 show that during the 7 to 21 days the strength of the flexural concrete specimen is escalating as expected, where on 21 days it managed to reach the $3.57 \mathrm{MPa}$. But on the 28th days, it appears that the specimen failed to reach the maximum strength of the concrete. The flexural strength failed at the 28th day due to a wrong mixing of cement, sand, gravel and water. The possibility of putting too much water during the assimilation of concrete is one of the possibilities that caused this result. The effect of too much mixing of water causes sand streaks which grounds up to excess water bleeding that washed up cement paste.

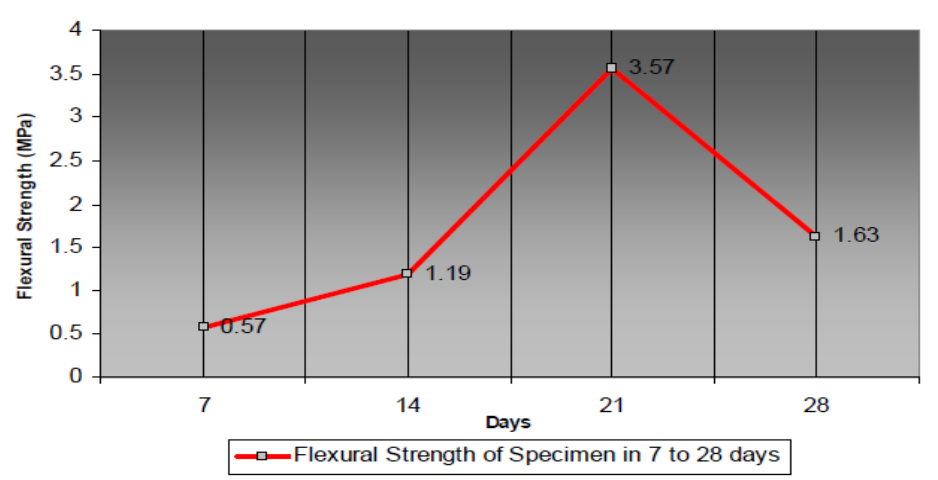

Figure 1. Flexural strength of sample concrete 


\subsection{Compressive strength}

Table 4 shows that as the curing day progress, the strength of the specimen cured for 7, 14, 21 and 28 days increases.

As presented, it's very obvious that the strength follows upon the length of day of the specimen been cured, and as of 21 days, one of the two concrete specimen gain 19.56 $\mathrm{MPa}$, exceeding the expected outline specification of $17.23 \mathrm{MPa}$. The 28 old day's specimen achieved a 23.47 MPa and 16.07 MPa.

Table 4. Compressive strength

\begin{tabular}{|c|c|c|}
\hline Identification & $\begin{array}{c}\text { Age } \\
\text { (days) }\end{array}$ & $\begin{array}{c}\text { Compressive strength } \\
\text { (MPa) }\end{array}$ \\
\hline \multirow{2}{*}{$\mathrm{A}$} & 7 & 14.31 \\
\cline { 2 - 3 } & 7 & 12.98 \\
\hline \multirow{2}{*}{$\mathrm{B}$} & 14 & 17.10 \\
\cline { 2 - 3 } & 14 & 18.00 \\
\hline \multirow{2}{*}{$\mathrm{C}$} & 21 & 19.56 \\
\cline { 2 - 3 } & 21 & 16.04 \\
\hline \multirow{2}{*}{$\mathrm{D}$} & 28 & 16.07 \\
\cline { 2 - 3 } & 28 & 23.47 \\
\hline
\end{tabular}

\subsection{Temperature analysis of plastic}

Thermoplastics require heat to make them formable and after cooling, retain the shape they were formed into. These materials can be reheated and reformed into new shapes a number of times without significant change in their properties. Most thermoplastics consist of very long main chains of carbon atoms covalently bonded together. Sometimes nitrogen, oxygen or sulfur atoms are also covalently bonded in the main molecular chain. Figure 2 shows the behavior for a group of thermoplastics as the temperature increases, the secondary bonding forces between the molecular chains become weaker and the strength of the thermoplastic decreases. When a thermoplastic material is heated its strength decreases greatly due to a pronounced decrease in the secondary bonding forces. It shows this effect for polymethyl methacrylate (PMMA), which has a temperature of about $100^{\circ} \mathrm{C}$. The tensile strength of PMMA is about $7 \mathrm{ksi}$ at $86^{\circ} \mathrm{C}$, which is below its temperature and decreases to about $4 \mathrm{ksi}$ at $122^{\circ} \mathrm{C}$, which is about its temperature. The maximum - use temperatures for some thermoplastics are listed below.

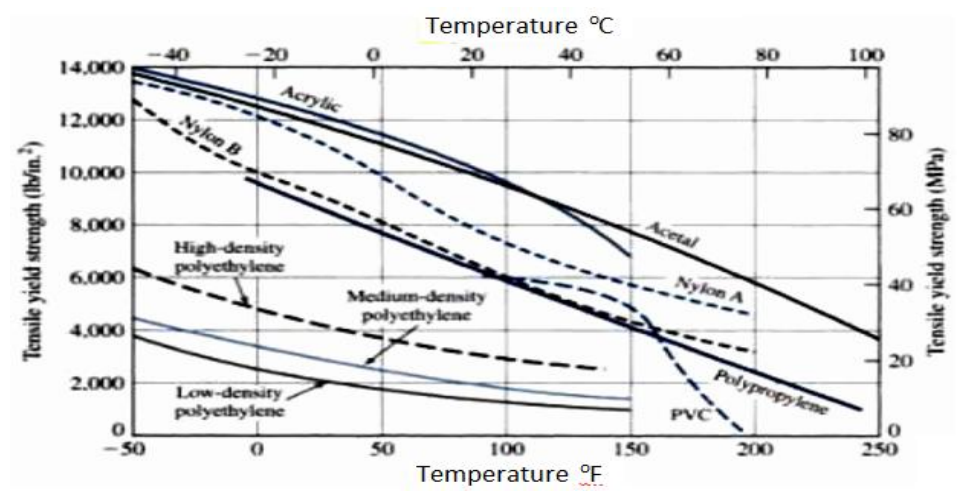

Figure 2. Effects of temperature 


\section{Conclusion}

Thermoplastic as a substitute to fine aggregate to concrete mixture has shown unusual characteristic upon accumulation of water in the mixture for the material had floated on the surface of the water, nevertheless, upon the completion of mixing the material has suitably bonded to the mixture. In the analysis of its grain particle, in comparison to sand, which is one of the major components of concrete mixture, thermoplastic, imply significant lightness in terms of its mass evaluation. Overall, the effect of the thermoplastic on the properties of the specimen was acceptable. The thermoplastic material substituting the $5 \%$ of sand, the fine aggregate of mixture managed to attain the required strength in accordance with ASTM standard C62 - 97 specification of wall panel, which is $2500 \mathrm{psi}(17.24 \mathrm{MPa})$. On its 28th day the specimen with the thermoplastic fine aggregate attain at least $19 \mathrm{MPa}$ average for both of the tested specimen, which exceeded that of the design specification.

The thermoplastic material copes up with the ASTM standard specifications with no adverse effects on the properties needed by a concrete mixture for wall panels (CHB's, bricks and mortars). It can be concluded that the positives are significant enough to justify the use of thermoplastic (waste plastic material) in concrete mixture. Although much to the expectation in flexural strength which failed on the 28th days curing, the research is still looking on the strength of compressive strength which is the more important characteristics of the concrete.

Thermoplastic is economically feasible compared to fine aggregate since the research focuses only on material that are considered waste and not the so - called 'virgin' plastic that can be very expensive if altered to the sand. The scrap value of the plastic would even add employment to those people living in slump areas where most waste plastic is being heaved.

In terms of heat and temperature of the thermoplastic, it is concluded that with an increase in the stretching temperature up to a definite limit $\left(170^{\circ} \mathrm{C}\right)$ the tensile strength of PETP and other fibers from crystalline polymers increases. However, at higher temperatures $\left(230^{\circ} \mathrm{C}\right)$ the strength diminishes. This is evidently due to a reduction in the density of the intercrystallite regions of the fibrils, in which there is greater probability of polymer failure originating. Such behavior of fiber made from PETP at elevated stretching temperatures is evidently associated both with the polymer structure and with its low molecular weight.

\section{Appendix}

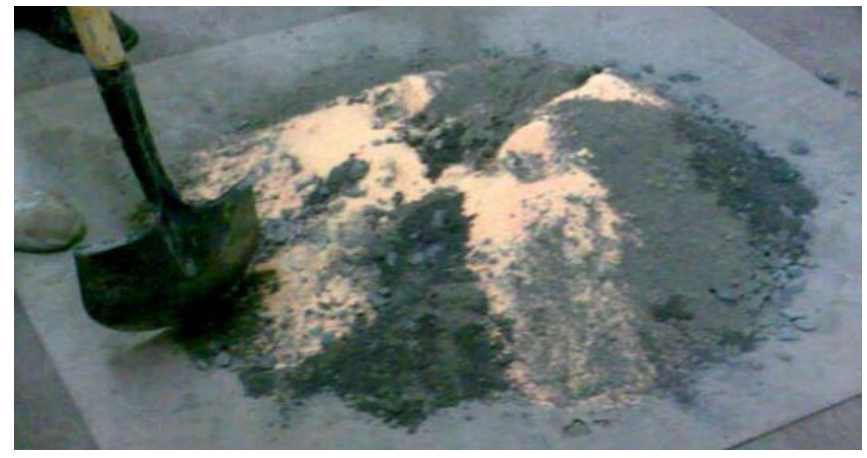

Figure 3. Mixing the thermoplastic 


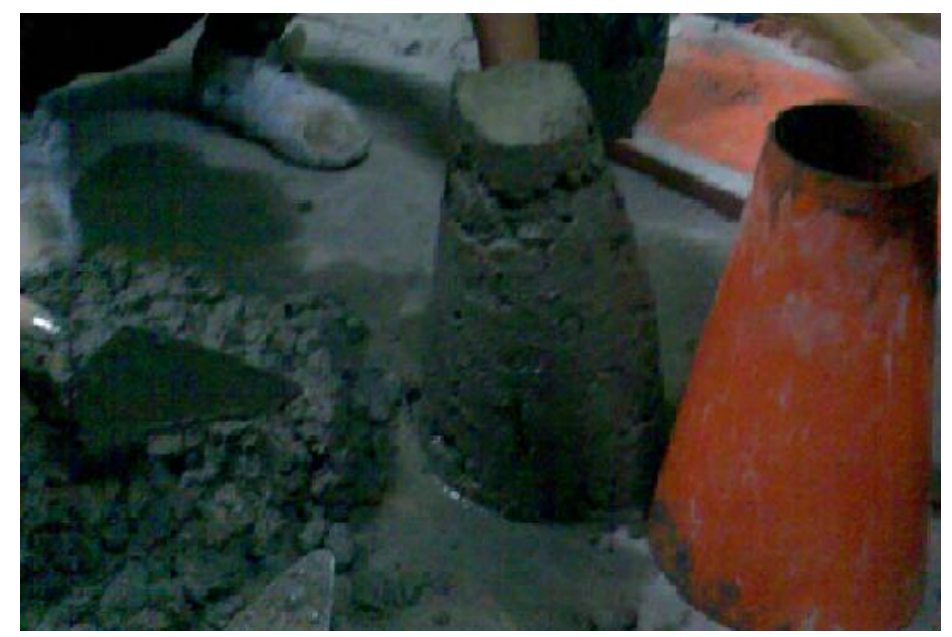

Figure 4. Slump testing the concrete mixture

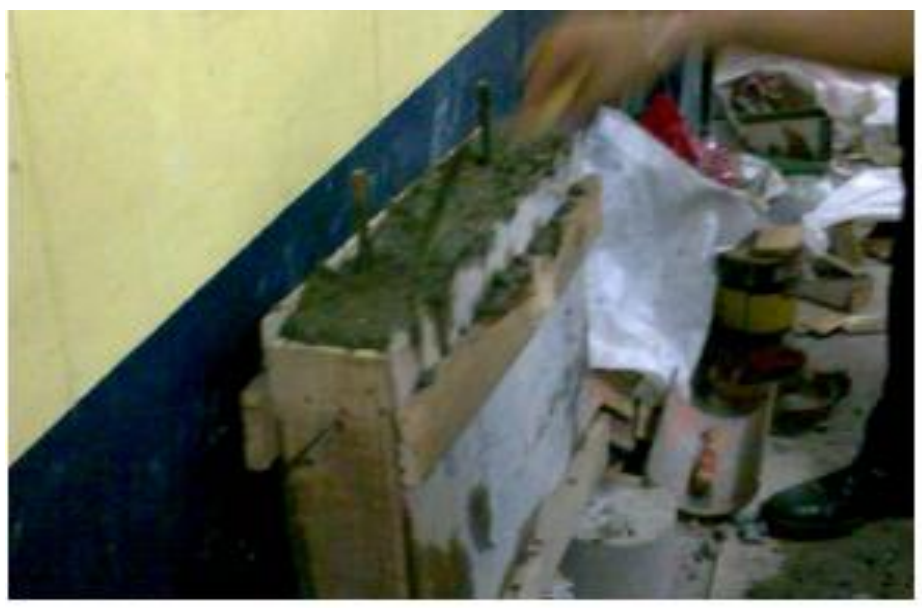

Figure 5. Pouring the mixture into the forms

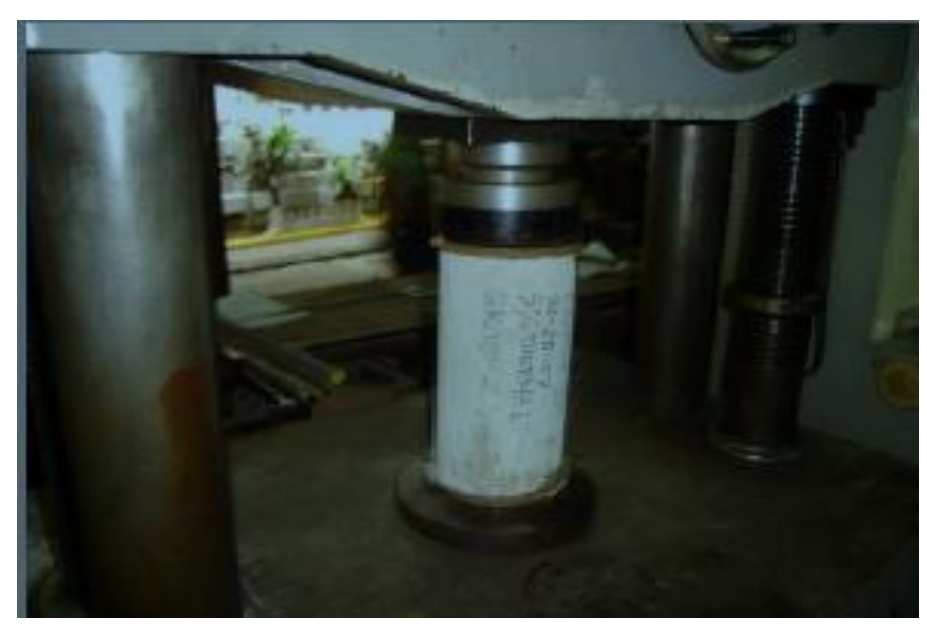

Figure 6. Testing the compressive strength 


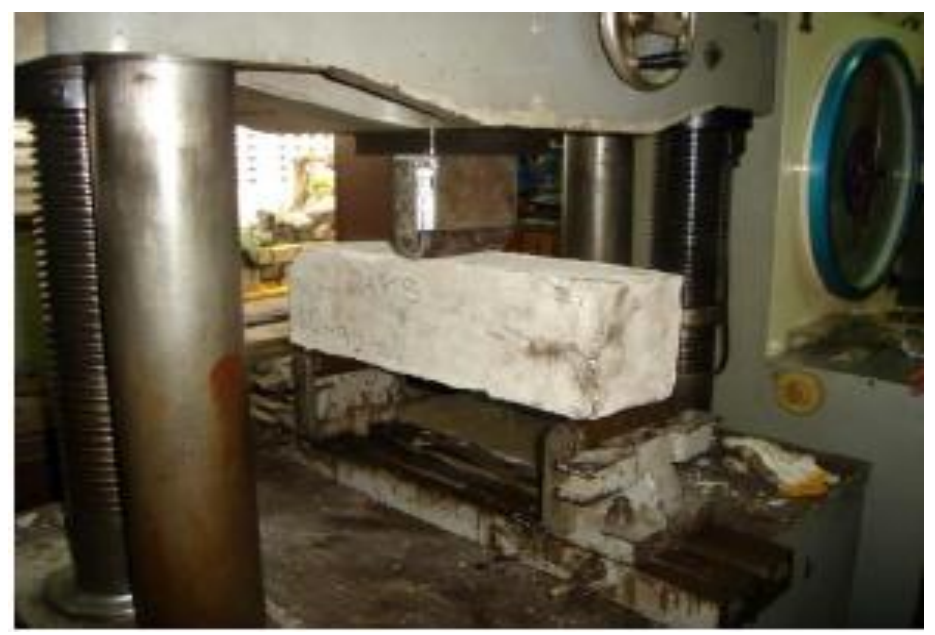

Figure 7. Testing the flexural strength

\section{References}

[1] T. U. Ganiron Jr, "Influence of Polymer Fiber on Strength of Concrete", International Journal of Advanced Science and Technology, vol. 55, (2013).

[2] M. Frigione, "Recycling of PET Bottles as Fine Aggregate in Concrete", Waste Management, vol. 30, no. 6, (2010).

[3] T. U. Ganiron Jr, "Investigation on the use of Coco Coir Polypropylene as Thermal Insulator", International Journal of Advanced Science and Technology, vol. 59, (2013).

[4] T. U. Ganiron Jr, "An Investigation of Moisture Performance of Sawdust and Banana Peels Ply board as NonVeneer Panel”, International Journal of u- and e- Service, Science and Technology, vol. 6, no. 3, (2013).

[5] P. Asokan, "Assessing the Recycling Potential of Glass Fibre Reinforced Plastic Waste in Concrete and Cement Composites", Journal of Cleaner Production, vol. 17, no. 9, (2009).

[6] T. U. Ganiron Jr, "Utilization and End-Users Acceptability of Compressed Lahar Sediment Blocks as Wall Panel for Low Cost Housing", WSEAS Transactions on Environment and Development, vol. 9, no. 3, (2013).

[7] D. Little and A. Bhasin, "Exploring Mechanism of Healing in Asphalt Mixtures and Quantifying its Impact", vol. 100, (2007).

[8] P. Panyakapoand M. Panyakapo, "Reuse of Thermosetting Plastic Waste for Lightweight Concrete", Waste Management, vol. 28, no. 9, (2008).

[9] T. Ganiron Jr and N. Ucol-Ganiron, "Recycled Glass Bottles: An Alternative Fine Aggregates for Concrete Mixture", Proceedings of the 4th International Conference of Euro Asia Civil Engineering Forum, (2013) June 26-27; Singapore.

[10] T. U. Ganiron Jr, "Technical Specification of Concrete Hollow Blocks with Coconut Shells and Fiber as Aggregate", Proceedings of the 1st International Concrete Sustainability, (2013) May 27; Tokyo, Japan.

[11] T. U. Ganiron Jr, "Recycling of Waste Coconut Shells as Substitute for Aggregates in Mix Proportioning of Concrete Hollow Blocks", WSEAS Transactions on Environment and Development, vol. 9, no. 4, (2013).

[12] A. Al-Hadidy and T. Yi-qiu, "Effect of Polyethylene on Life of Flexible Pavements", Construction and Building Materials, vol. 23, no. 3, (2009).

[13] J. Correia, "Recycling of FRP Composites: Reusing Fine GFRP Waste in Concrete Mixtures", Journal of Cleaner Production, vol. 19, no. 15, (2011).

[14] T. U. Ganiron Jr, "Effects of Rice Hush as Substitute for Fine Aggregate in Concrete Mixture", International Journal of Advanced Science and Technology, vol. 58, (2013).

[15] J. Zelić, "Properties of Concrete Pavements", Cement and Concrete Research, vol. 35, no. 12, (2005).

[16] T. U. Ganiron Jr, "Testing Water Vapour Permeability of Sawdust and Banana Peels Ply Board as NonVeneer Panel", International Journal of Construction Engineering and Management, vol. 2, no. 2, (2013).

[17] T. U. Ganiron Jr, "Recycled Window Glass for Non-Load Bearing Walls", International Journal of Innovation, Management and Technology, vol. 3, no. 6, (2012). 


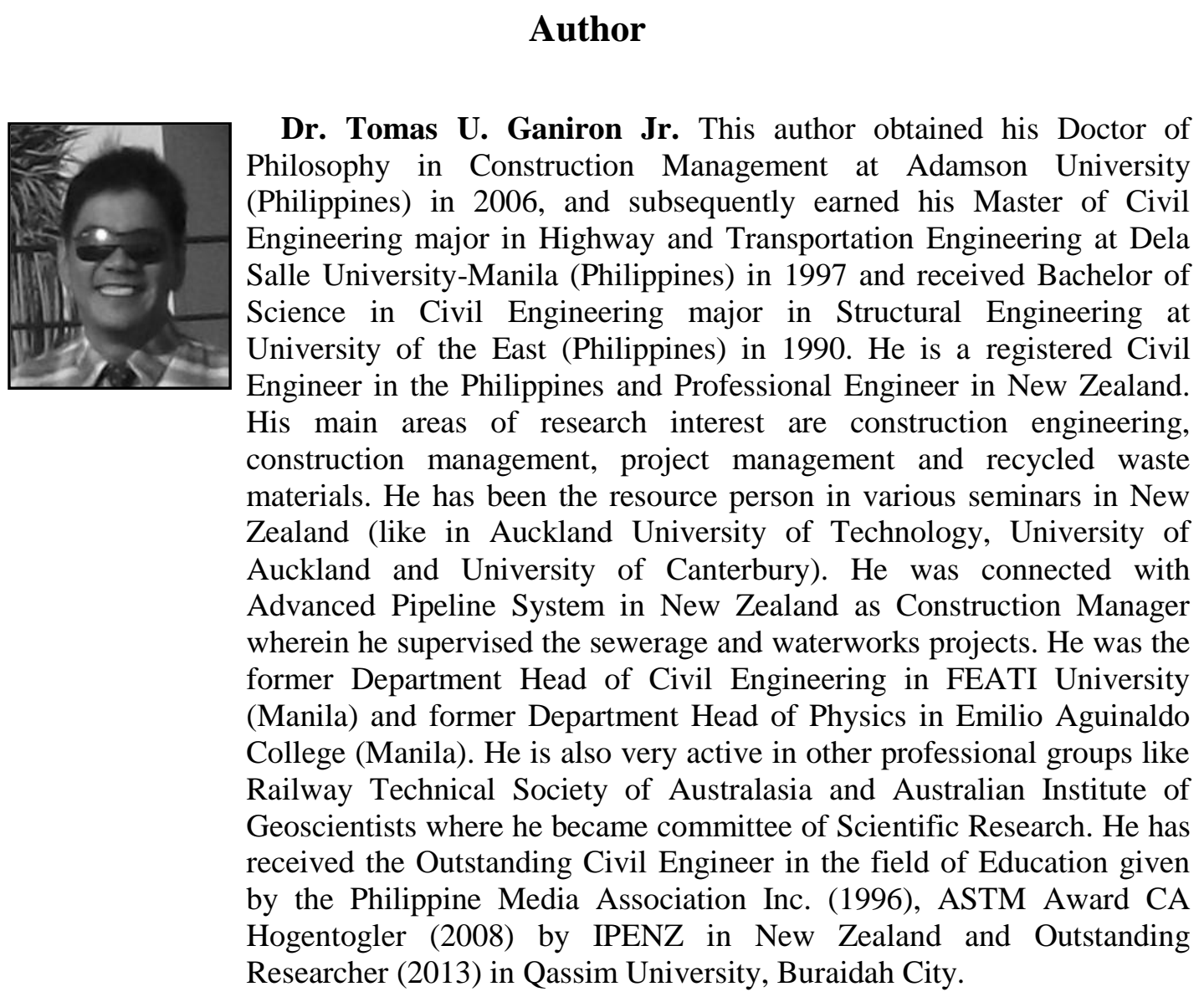


International Journal of Advanced Science and Technology Vol.62, (2014) 